REGARDS

SUR L'ECONOMIE ALLEMAND

BULLETIN ECONOMIQUE DU CRRAC
Regards sur l'économie allemande

Bulletin économique du CIRAC

$105 \mid 2012$

Varia

\title{
B2C : montée en puissance des mobiles
}

Isabelle Bourgeois

\section{CpenEdition}

Journals

Édition électronique

URL : https://journals.openedition.org/rea/4426

DOI : $10.4000 /$ rea.4426

ISBN : 978-2-8218-1420-2

ISSN : 1965-0787

Éditeur

CIRAC

Édition imprimée

Date de publication : 11 juillet 2012

Pagination : 38

ISSN : 1156-8992

Référence électronique

Isabelle Bourgeois, «B2C : montée en puissance des mobiles », Regards sur l'économie allemande [En ligne], 105 | juillet 2012, mis en ligne le 19 juillet 2012, consulté le 28 juin 2022. URL : http:// journals.openedition.org/rea/4426 ; DOI : https://doi.org/10.4000/rea.4426

Ce document a été généré automatiquement le 29 septembre 2020.

(C) CIRAC 


\title{
B2C : montée en puissance des mobiles
}

\author{
Isabelle Bourgeois
}

1 En Allemagne aussi, le shopping en ligne a le vent en poupe. 41 millions de consommateurs on effectué des achats via Internet en 2011, soit 3 millions de plus que l'année précédente. L'engouement pour les téléphones mobiles est particulièrement net : 2,9 millions d'Allemands l'ont utilisé en 2011 pour passer commande, soit plus du double qu'en 2010. C'est ce qu'il ressort l'Online Shopping Survey (OSS) 2012 réalisé en janvier/février auprès d'un échantillon de 1179 personnes âgées de 14 à 69 ans par ENIGMA GfK.

2 Les produits et services les plus demandés sont toujours l'habillement (19,3 millions), suivis par les livres (18,6 millions), la réservation de billets pour diverses manifestations (14,9 millions), les jeux (10,6 millions) et les supports musicaux (10,4 millions). La plus forte hausse en un an a été enregistrée par l'habillement $(+2,1$ millions), les parfums et cosmétiques $(+1,8$ million $)$, de même que la bijouterie/ horlogerie ( $+1,6$ million).

3 Amazon reste le site de prédilection des Allemands (27,7 millions de clients), suivi d'Ebay (21 millions) et de Weltbild (7 millions). Quant au vépéciste Otto, il se positionne désormais ex aequo avec ce dernier. Un nouveau s'est positionné cinquième : Zalando.

4 C'est la forte progression des usages mobiles qui explique la montée en puissance des portables pour les achats en ligne. 14,7 millions d'Allemands consultent Internet via leur mobile ( $84 \%$ d'entre possèdent un smartphone). Et 5,1 millions l'utilisent pour s'informer avant un achat éventuel, en ligne ou non. Les catégories de biens et services sur lesquels ils se renseignent diffèrent de celles qu'ils achètent. Il s'agit, par ordre décroissant, de places de concert ou autres, de livres, de téléphones portables, de vêtements, chaussures et accessoires, ainsi que de l'offre de chambres d'hôtel. Les Allemands aussi se sont approprié les services du mobile pour mieux faire jouer la concurrence... (IB) 
INDEX

Mots-clés : nouvelles technologies, TIC, télévision, média, information, politique des médias, commerce électronique, e-commerce, téléphonie mobile, marché, commerce 